\title{
UTILIZAÇÃO DE MODELAGEM NUMÉRICA PARA O ESTUDO DA DISPERSÃO DE POLUENTES EMITIDOS PELA USINA TERMOELÉTRICA PRESIDENTE MÉDICI
}

\author{
Sheila Radann Paz e Rita Cássia Marques Alves
}

Centro Estadual de Pesquisas em Sensoriamento Remoto e Meteorologia, Universidade Federal do Rio Grande do Sul, CP 15044, 91501-970 Porto Alegre - RS, Brasil

Elba Calesso Teixeira* e Juliana Braga Dallarosa

Fundação Estadual de Proteção Ambiental Henrique Luís Roessler/RS, Rua Carlos Chagas, 55, 90030-020 Porto Alegre - RS, Brasil

Recebido em 14/8/06; aceito em 2/3/07; publicado na web em 30/7/07

\begin{abstract}
USE OF NUMERICAL MODELLING IN THE STUDY OF DISPERSION OF POLLUTANTS EMITTED BY THE PRESIDENTE MEDICI COAL POWER STATION. The purpose of the present study is to evaluate the atmospheric behavior in the dispersion of the pollutants $\mathrm{SO}_{2}, \mathrm{PM}_{10}$ and $\mathrm{NO}_{\mathrm{x}}$ emitted by the President Medici power plant in Candiota, RS. The RAMS atmospheric model was applied and the simulations were conducted from april in 20 to 24, 2004. The concentrations of the pollutants simulated by RAMS were compared with the data measured at the air quality monitoring stations. The results showed significant influence of the emissions generated by the power plant on the concentration of the pollutants.
\end{abstract}

Keywords: mesoscale atmospheric modeling; dispersion of pollutants; meteorological conditions.

\section{INTRODUÇÃO}

A implementação de projetos elétricos de certos tipos de fontes energéticas, como carvão, hidroeletricidade e gás natural pode causar sérios problemas sócio-ambientais, como perdas de biodiversidade, deslocamento de populações, chuva ácida, poluição do ar, efeito estufa etc. O estado do Rio Grande do Sul é detentor de uma das maiores reservas carboníferas do Brasil, pois concentra $38 \%$ da reserva total de carvão do Brasil, em uma área de $2500 \mathrm{~km}^{2}$, totalizando aproximadamente 12,3 bilhões de $\mathrm{t}$, sendo $30 \%$ mineráveis a céu aberto ${ }^{1}$. O impacto ambiental das emissões de poluentes, decorrentes da combustão do carvão mineral está associado aos processos de dispersão destes poluentes na atmosfera. A trajetória dos poluentes atmosféricos e, conseqüentemente, sua concentração ambiental são determinadas em função das condições meteorológicas, as quais são interligadas à topografia, ao uso e ocupação do solo.

A evolução da concentração de um determinado constituinte atmosférico pode ser resolvida através da solução da equação de conservação da massa. Esta equação envolve os processos de advecção, difusão, reações químicas, fontes e sorvedouros, e a avaliação do comportamento dos constituintes atmosféricos pode ser resolvida numericamente através da aplicação de modelos numéricos de dispersão.

No que se refere à previsão de dispersão de poluentes, os modelos meteorológicos buscam representar a interação entre os processos de dispersão do material emitido e o comportamento deste diante do estado da atmosfera e das características físicas do ambiente. Estas características podem ser: a cobertura do terreno, umidade do solo, presença de centros urbanos, proximidade com áreas lacustres e marítimas e influência da topografia. Estudos mostram que a distribuição espacial dos tipos de superfície interfere diretamente em gradientes horizontais do fluxo de calor sensível e latente, assim como de temperatura do ar na camada limite planetária (CLP) ${ }^{2}$.

Nicholls et al. ${ }^{3}$ têm realizado estudos de qualidade do ar utili-

*e-mail: gerpro.pesquisa@ fepam.rs.gov.br zando o modelo de mesoescala "Regional Atmospheric Modeling System (RAMS)" em áreas urbanas, como Lago Michigan, entre outros. O modelo RAMS é um modelo de mesoescala de área limitada, desenvolvido para simulação e previsão de fenômenos meteorológicos ${ }^{4}$, designados para simular circulações atmosféricas que vão desde a micro até a grande escala.

Vários estudos têm sido desenvolvidos no Brasil empregando modelo RAMS. Dentre estes, citam-se o trabalho realizado por Freitas 5 , que utilizou o modelo RAMS para verificar a influência de circulações locais na dispersão de poluentes considerando a região Metropolitana de São Paulo; Alves ${ }^{6}$ desenvolveu um estudo da simulação da circulação atmosférica para a Usina Termoelétrica de Candiota, utilizou dois experimentos numéricos, sendo que o primeiro foi inicializado sem forçante externo, e mostrou que o modelo utilizado, o RAMS, é altamente sensível a mudanças topográficas.

O presente trabalho teve como objetivo o estudo do comportamento atmosférico nos processos de dispersão dos poluentes emitidos pela Usina Termoelétrica Presidente Médici, Candiota - RS através de modelagem numérica. Neste estudo, foi aplicado o modelo de mesoescala RAMS para simular as condições atmosféricas e as concentrações de dióxido de enxofre $\left(\mathrm{SO}_{2}\right)$, material particulado $\left(\mathrm{PM}_{10}\right)$ e óxido de nitrogênio $\left(\mathrm{NO}_{\mathrm{x}}\right)$. O modelo RAMS foi inicializado com dados das análises do modelo global do Centro de Previsão do Tempo e Estudos Climáticos do Instituto Nacional de Pesquisas Espaciais (CPTEC/INPE). Os resultados simulados foram comparados com os dados observados na região para o período estudado.

\section{PARTE EXPERIMENTAL}

O estudo da dispersão de poluentes foi realizado utilizando o modelo de Mesoescala RAMS é um modelo numérico de múltipla finalidade, desenvolvido na Universidade Estadual do Colorado, EUA ("CSU - Colorado State University"), designado para simular circulações atmosféricas que vão desde a micro até 
a grande escala ${ }^{4}$.

O modelo RAMS, versão $4.4^{7}$ foi inicializado com os dados do modelo global do CPTEC/INPE, com resolução de $1,875^{\circ}$ na horizontal, com um intervalo de $12 \mathrm{~h}$, para a inicialização heterogênea. O período simulado foi de 20 a 24 de abril de 2004. Quatro grades centradas nas coordenadas da Usina Termoelétrica Presidente Médici - UTPM $\left(31.50^{\circ} \mathrm{S}\right.$ e $\left.53.68^{\circ} \mathrm{W}\right)$ (Figura 1$)$ foram aninhadas, com espaçamento de grade horizontal de 32, 8, 4 e 0,5 $\mathrm{km}$ para as grades 1, 2, 3 e 4, respectivamente. Na vertical, foram utilizados 30 níveis em coordenadas sigma, com espaçamento inicial de $30 \mathrm{~m}$ próximo à superfície, e uma amplificação por um fator de 1,1 até atingir a $1000 \mathrm{~m}$ de altitude. Após esta altura, o espaçamento foi mantido constante e igual a 1000 $(\Delta \mathrm{z}=1000)$. Foram utilizadas na simulação 7 camadas do solo, com grau de saturação entre 0,60 e $0,42 \%$, considerando solo homogêneo (franco argiloso arenoso) e vegetação do tipo grama curta.

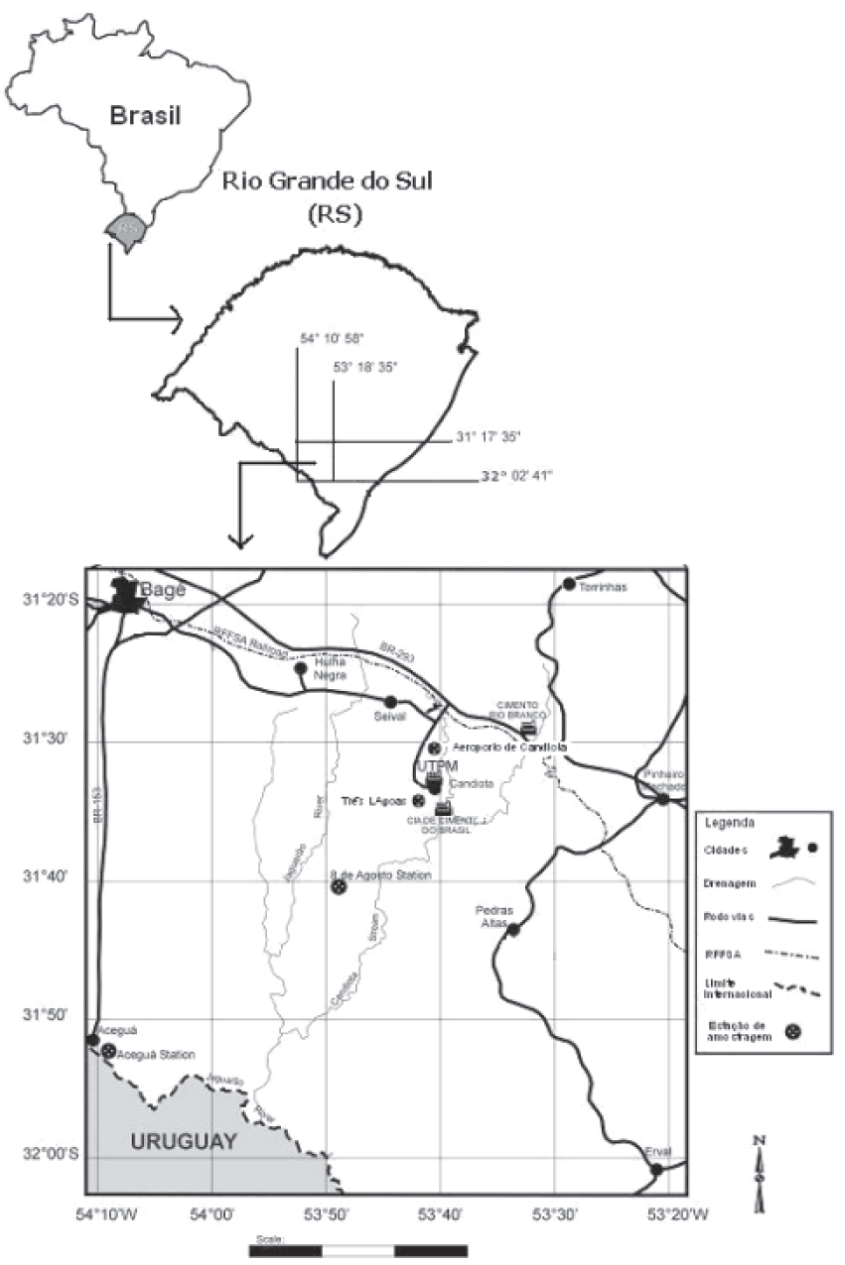

Figura 1. Mapa de localização da área de estudo. Candiota - RS

As concentrações simuladas dos poluentes estudados $\left(\mathrm{SO}_{2}, \mathrm{PM}_{10}\right.$ e $\mathrm{NO}_{\mathrm{x}}$ ) foram obtidas através da implementação de uma sub-rotina de dispersão, a qual foi estruturada em modelagem euleriana. $\mathrm{Na}$ modelagem euleriana o transporte de poluentes é estudado em termos de uma equação diferencial parcial para a conservação da massa da substância considerada, sendo esta resolvida para uma grade fixa no tempo e no espaço. Com isto, fornece valores médios de concentração para os poluentes considerados, em um ponto no espaço. A partir das equações de conservação é possível obter um modelo matemático da dispersão de uma fonte. Com o avanço no tempo, obtém-se o comportamento e a trajetória destes poluentes, considerando as condições atmosféricas.
Para a determinação do transporte de uma substância presente em uma massa de ar, a sub-rotina implementada no modelo RAMS resolve a equação de transporte para um constituinte atmosférico, aqui representado genericamente pela letra $\mathrm{C}^{8}$ :

$$
\frac{\partial \overline{\mathrm{C}}}{\partial \mathrm{t}}=\left(\frac{\partial \overline{\mathrm{C}}}{\partial \mathrm{t}}\right)_{\mathrm{adv}}+\left(\frac{\partial \overline{\mathrm{C}}}{\partial \mathrm{t}}\right)_{\text {turb }}+\overline{\mathrm{Q}}_{[\mathrm{c}]}
$$

onde $\frac{\partial \overline{\mathrm{C}}}{\partial \mathrm{t}}$ é o termo associado à advecção de grande escala, definido por:

$\left(\frac{\partial \overline{\mathrm{C}}}{\partial \mathrm{t}}\right)_{\mathrm{adv}}=-\bar{u}_{i} \frac{\partial \bar{C}}{\partial x_{i}}$

sendo $\overline{\mathrm{C}}$ o valor médio do escalar $\mathrm{C}$ e $\bar{u}_{i}$ o componente genérico $i$ da velocidade média do vento, indicado pela ocorrência de uma soma no domínio $[1,3]$ de tal forma que $\mathrm{u}_{1}=u, \mathrm{u}_{2}=v$ e $\mathrm{u}_{3}=w$ e $\mathrm{x}_{1}=x, \mathrm{x}_{2}$ $=y$ e $\mathrm{x}_{3}=z$.

$\left(\frac{\partial \overline{\mathrm{C}}}{\partial \mathrm{t}}\right)_{\text {turb }}$ é o termo associado ao transporte turbulento na camada limite, definido por:

$\left(\frac{\partial \overline{\mathbf{C}}}{\partial \mathrm{t}}\right)_{\text {turb }}=-\frac{1}{\rho_{o}} \frac{\partial\left(\rho_{o} \overline{u_{i}^{\prime} C^{\prime}}\right)}{\partial x_{i}}$

sendo $\rho_{0}$ a densidade do ar no estado básico, $u^{\prime} C_{i}^{\prime}$ o fluxo turbulento transportando o escalar $\mathrm{C}$ através do momento $u_{i}$, e i, j os índices que designam as três dimensões espaciais $(1,2,3)$ utilizando a notação soma.

$\overline{\mathrm{Q}}_{\mathrm{ic}]}$ representa o termo fonte inserido na quarta grade do modelo, expresso em unidades de $\mathrm{mg} \mathrm{m}^{-3}$. Este termo é expresso por:

$\overline{\mathrm{Q}}_{[\mathrm{c}]}=\frac{Q_{o}}{\rho_{o} V}$

sendo $Q_{o}$ a taxa de emissão da fonte e $V$ o volume dos gases emitidos. $\mathrm{O}$ volume é dado por $V=\Delta x . \Delta y . \Delta z$.

Os dados da taxa de emissão da UTPM utilizados neste estudo foram de $1000 \mathrm{~g} \mathrm{~s}^{-1}$ para dióxido de enxofre $\left(\mathrm{SO}_{2}\right), 944 \mathrm{~g} \mathrm{~s}^{-1}$ para $\mathrm{PM}_{10}$ e de $980 \mathrm{~g} \mathrm{~s}^{-1}$ para óxidos de nitrogênio $\left(\mathrm{NO}_{\mathrm{x}}\right)$. Os dados foram fornecidos pela Companhia de Geração Térmica de Energia e Eletricidade (CGTEE) e foram calculados com base na quantidade diária de carvão utilizado pela usina de 3,02 x 10 teor de enxofre. As emissões são lançadas pela chaminé da usina a uma altura de $150 \mathrm{~m}$, com temperatura de exaustão dos gases de $420 \mathrm{~K}$ e velocidade de saída de $20 \mathrm{~m} \mathrm{~s}^{-1}$.

Para a validação do modelo foram realizadas amostragens do material particulado $<10 \mu \mathrm{m}$ através de amostrador de Grandes Volumes (HV $\mathrm{PM}_{10}$ - marca Energética) no período de 20 a 30 de abril de 2004 nas estações de Três Lagoas, Aceguá e 8 de Agosto (Tabela 1). O amostrador HV PM $_{10}$ coleta as partículas por impactação, operando com uma vazão/fluxo de $1,13 \mathrm{~m}^{3} \mathrm{~L}^{-1}$, sob condições normais de temperatura e pressão. Filtros de quatzo (Whatman, QM-A, 20,3 x 25,4 $\mathrm{cm}$ ) foram utilizados para coleta do material particulado, sendo estes filtros identificados e estocados por $24 \mathrm{~h}$ em câmara de pesagem antes e depois da amostragem, sob condições controladas de temperatura e umidade (USEPA 1994). Os dados de concentração de $\mathrm{SO}_{2}$ foram obtidos a partir dos amostradores automáticos de gases instalados nas estações de monitoramento do ar Três Lagoas e Aeroporto de Candiota, da CGTEE, localizadas na região de Candiota (Tabela 1).

Os dados de condições meteorológicas foram obtidos através da estação meteorológica automática instalada na cidade de Aceguá, 
Tabela 1. Coordenadas das estações de qualidade do ar da CGTEE localizadas em Candiota - RS

\begin{tabular}{lccc}
\hline Estações & \multicolumn{2}{c}{ Coordenadas Geográficas } & Altitude \\
& X (latitude) & Y (longitude) & $(\mathrm{m})$ \\
\hline Aeroporto de Candiota & $-31^{\circ} 30^{\prime} 12^{\prime \prime}$ & $-53^{\circ} 42^{\prime} 04^{\prime \prime}$ & 232 \\
Aceguá & $-31^{\circ} 52^{\prime} 52^{\prime}$ & $-54^{\circ} 09^{\prime} 21^{\prime}$ & 265 \\
8 de Agosto & $-31^{\circ} 40^{\prime} 44^{\prime}$ & $-53^{\circ} 49^{\prime} 21^{\prime \prime}$ & 261 \\
Três Lagoas & $-31^{\circ} 36^{\prime} 11^{\prime}$, & $-53^{\circ} 44^{\prime} 12^{\prime}$ & 215 \\
\hline
\end{tabular}

na região de Candiota (Figura 1). Os parâmetros meteorológicos obtidos foram temperatura do ar, precipitação atmosférica, umidade relativa e umidade do solo.

As análises sinóticas das condições atmosféricas para o período de 20 a 25/4/2004 foram realizadas utilizando imagens do satélite GOES - 12 no canal Infravermelho, obtidas através do Laboratório Master do IAG/USP e com campos meteorológicos simulados com o modelo RAMS. Os campos simulados para esta análise foram extraídos da primeira grade do modelo (resolução horizontal de $32 \mathrm{~km}), 14,3 \mathrm{~m}$ acima da superfície.

Os parâmetros meteorológicos obtidos na saída do modelo, assim como os campos de concentração de $\mathrm{SO}_{2}, \mathrm{NO}_{\mathrm{x}}$ e $\mathrm{PM}_{10}$ obtidos pelo RAMS após a implementação da sub-rotina, foram extraídos da quarta grade do modelo (resolução de 500 m), a 14,3 m da superfície. Estes resultados foram obtidos através do software de visualização GRADS ("Grid Analisys and Display System”), para os pontos de grade referentes às coordenadas das estações de monitoramento, na região de Candiota (Tabela 1).

\section{RESULTADOS E DISCUSSÂO}

\section{Análise da circulação atmosférica}

Os resultados da análise sinótica realizada para o período de 20 a 25 de abril de 2004 mostram que no dia 20, as condições atmosféricas predominantes foram de ausência de nebulosidade em praticamente todo Rio Grande do Sul. No horário das 02:45 UTC, do dia 20 de abril verificou-se que a zona de baixa pressão em $29.5^{\circ} \mathrm{S}$ e $49.8^{\circ} \mathrm{W}$ estava associada à passagem de uma frente fria que, neste horário, estava se direcionando para o oceano. Os ventos na fronteira com o Uruguai apresentavam-se do quadrante sudoeste, relativamente fracos, com intensidade da ordem de $2 \mathrm{~m} \mathrm{~s}^{-1}$. Às 15:00 UTC verificavam-se áreas de pressão relativamente altas (mas não muito organizadas) em $31^{\circ} \mathrm{S}$ e $56^{\circ} \mathrm{W}$ aproximando-se do RS, provocando a permanência de ventos fracos sobre praticamente todo o Estado.

No dia 21, nuvens esparsas avançaram sobre o extremo sul do Rio Grande do Sul, devido ao avanço das áreas de alta pressão sobre o Estado. A atuação deste sistema foi responsável pela circulação de intensidade moderada de leste, ocasionando aumento de nebulosidade associada à entrada de umidade do oceano. Às 15:00 UTC ventos do setor noroeste avançaram a partir da metade norte do Estado, ao passo em que a entrada de umidade do mar continuava sendo verificada no setor sul. A variação temporal de temperatura provocada pelo habitual aquecimento no período da tarde ocasionou ventos levemente mais intensos, variando entre 4 e $7 \mathrm{~m} \mathrm{~s}^{-1}$ em todo o Estado.

No dia seguinte (22/4) observou-se que a área de instabilidade ganhou força e se espalhou por todo o Estado, provocando aumento de nebulosidade, que avançou pelo setor sul e sudoeste devido à aproximação de uma zona de baixa pressão não organizada a partir do Uruguai. Os ventos apresentavam intensidade variando entre 6 e $11 \mathrm{~m} \mathrm{~s}^{-1}$. Às 15:00 UTC o centro de baixa pressão, agora mais evidente, sofreu deslocamento para nordeste e uma banda intensa de nebulosidade atingiu toda metade sul do Estado. A intensidade do vento nesta região variou de 8 a $12 \mathrm{~m} \mathrm{~s}^{-1}$.

Às 02:45 UTC do dia 23 observou-se que as áreas de instabilidade que estavam presentes há mais tempo, eram responsáveis pela organização de uma frente fria que rapidamente deslocou-se para latitudes menores. Ventos do quadrante NW com intensidade variando entre 5 e $8 \mathrm{~m} \mathrm{~s}^{-1}$ foram observados na fronteira sudoeste gaúcha. Com o afastamento do sistema frontal, a atmosfera iniciou um processo de gradual diminuição de nebulosidade, com ventos mudando o sentido para o quadrante sudoeste.

Às 02:45 UTC do dia 24 observou-se um aumento desorganizado de pressão em latitudes mais altas. O centro deste sistema, que se posicionava na altura no Uruguai, deslocava-se para o Atlântico e a circulação favorecia a entrada de umidade de regiões do Atlântico para dentro do Estado, provocando o aumento de nuvens em alguns setores do RS. Ventos de sudoeste passando à direção sul, com intensidade de $6 \mathrm{~m} \mathrm{~s}^{-1}$, foram identificados na região de Candiota.

Ao longo do dia 25/4, os ventos permaneceram do quadrante sul e foi observada uma rápida queda de pressão. No inicio do dia ainda era verificada muita nebulosidade no estado, devido ao suprimento de vapor de água.

\section{Comparação dos dados meteorológicos simulados e observados}

Dados meteorológicos coletados na Estação de Aceguá foram utilizados para a validação dos resultados meteorológicos simulados pelo modelo RAMS para a quarta grade (40 km x $40 \mathrm{~km})$, centrada nas coordenadas da usina termelétrica, na altura de 14,3 $\mathrm{m}$ da superfície.

Conforme citado no item anterior, as áreas de instabilidade que se formaram no dia 22/4 deram início a um sistema frontal, responsável pelo avanço de muitas nuvens para a região. Na Estação de Aceguá foram registrados $22 \mathrm{~mm}$ de precipitação, às $9 \mathrm{~h}$ locais (Figura 2a), sendo o total acumulado neste dia de $84 \mathrm{~mm}$. Nos demais dias de simulação, não houve registros de precipitação na região.
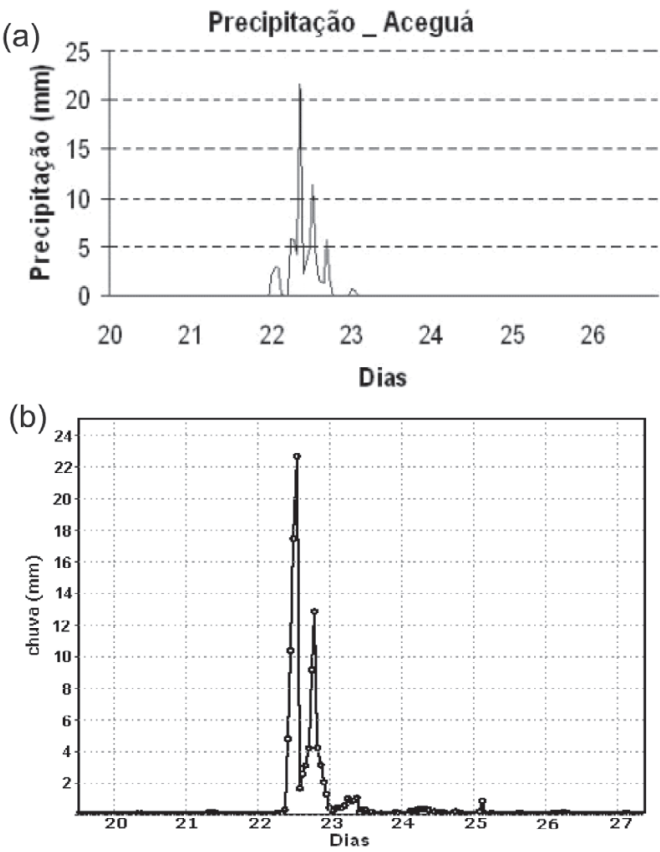

Figura 2. Evolução temporal da precipitação, obtido pela Estação Meteorológica de Aceguá (a) e simulado pelo modelo RAMS a nível de 14,3 $m$, acima da superfície ( $b$ ) 
A ocorrência de precipitação é um fator importante para o estudo da dispersão de poluentes, pois pode promover a remoção das partículas em suspensão na atmosfera, provocando a diminuição da concentração de poluentes. Na Figura 2b são apresentados os resultados da evolução temporal da precipitação para os dias da simulação, para as coordenadas da UTPM $\left(31.50^{\circ} \mathrm{S} 53.68^{\circ} \mathrm{W}\right)$. A precipitação simulada ultrapassou apenas $1,5 \mathrm{~mm}$ dos dados de precipitação observados, comparando com o valor máximo de chuva acumulada em $1 \mathrm{~h}$.

A instabilidade presente na região no início do período estudado foi responsável pelo aumento de temperatura que chegou a $27{ }^{\circ} \mathrm{C}$, na tarde do dia 21/4, depois de uma madrugada fria, com registros de 9,4 ${ }^{\circ} \mathrm{C}$, às $4 \mathrm{~h}$ locais. Dias 22 e 23/4, as temperaturas permaneceram em torno de $18{ }^{\circ} \mathrm{C}$, devido à intensa nebulosidade presente, voltando a cair na madrugada dos dias 24 e 25 , chegando a $8,3{ }^{\circ} \mathrm{C}$, devido ao sistema de pressão ligeiramente alta, responsável pela entrada de uma massa de ar mais fria e seca para a região. As temperaturas máximas nestes dias não ultrapassaram $18{ }^{\circ} \mathrm{C}$ (Figura 3a). Os resultados simulados mostram razoável coerência no que diz respeito à assinatura temporal da variável. Porém, apesar de estrutura semelhante, a grandeza da variável não foi satisfatoriamente modelada. A análise dos resultados simulados apresentou uma forte subestimação da variável nos dois dias 21 e 22/4/2004, período em que a atmosfera estava sob condições de nebulosidade. Nestes dias as temperaturas foram subestimadas em $6{ }^{\circ} \mathrm{C}$ em todos os horários. Nos demais dias, o comportamento simulado foi muito semelhante ao observado, $97 \%$. Os resultados mostraram que o modelo pode ter mascarado os processos advectivos da atmosfera, devido à ausência de radiação direta.

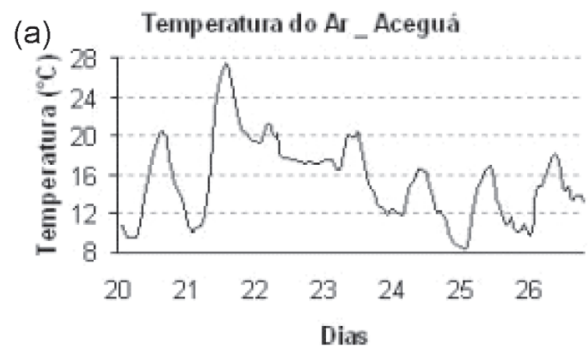

(b)

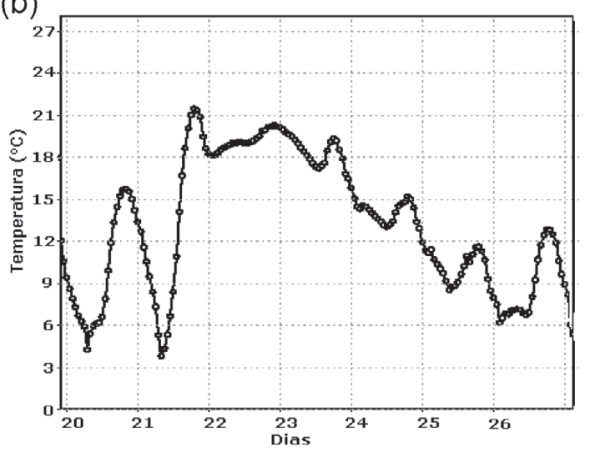

Figura 3. Evolução da temperatura do ar, ${ }^{\circ} \mathrm{C}$, obtida na Estação Meteorológica de Aceguá (a) e simulada com o modelo RAMS, em nível de 14,3 $m$ acima da superficie $(b)$

A Figura 4 apresenta a comparação da evolução temporal dos dados observados e simulados da umidade relativa do ar. Os dados simulados mostraram um comportamento distinto dos observados, principalmente para os dias 21 e 22/4/2004. Os valores de umidade relativa do ar observados na Estação Meteorológica de Aceguá para os dias 20, 21 e 22 de abril de 2004 ficaram em torno de 25 a $85 \%$. Os dados simulados com o modelo RAMS para o período citado variaram em torno de 57 a $100 \%$, o que mostra a superestimação dos resultados simulados para esta variável.
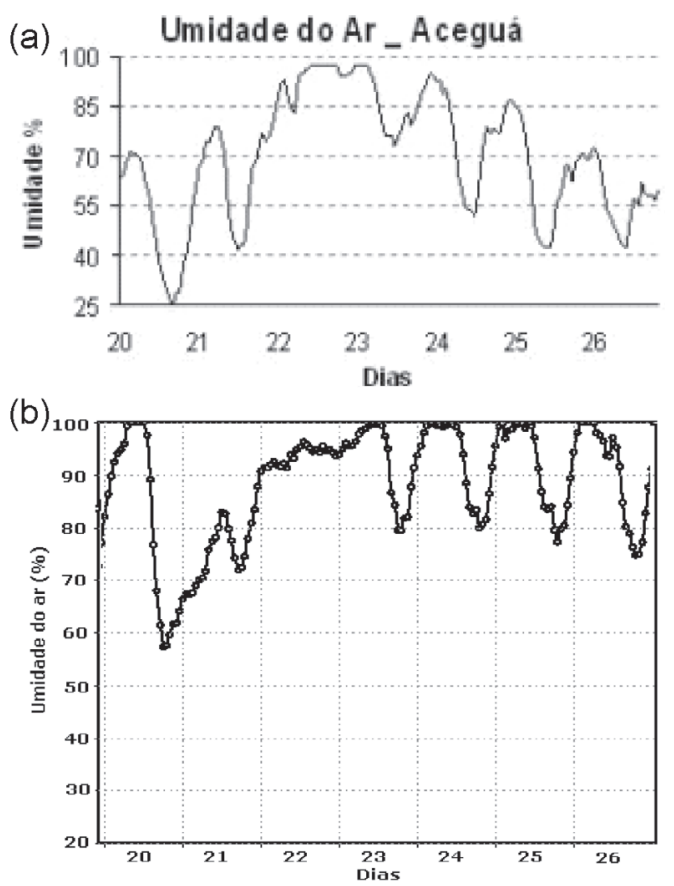

Figura 4. Evolução temporal da umidade relativa do ar, \%, obtida na Estação Meteorológica de Aceguá (a) e simulada com modelo RAMS, em nível de 14,3 $m$ acima da superficie (b)

De forma geral, os resultados observados e simulados, para as varáveis apresentadas foram satisfatórios. De acordo com outros estudos realizados utilizando o modelo RAMS ${ }^{6,9,10}$, os dados meteorológicos simulados foram validados, tendo em vista a boa reprodutibilidade dos fluxos sinóticos, bem como dos efeitos locais devidos à brisa marinha e à topografia.

\section{Análise das concentrações de $\mathrm{PM}_{10}, \mathrm{SO}_{2}$ e $\mathrm{NO}_{\mathrm{x}}$}

A análise das concentrações de poluentes foi realizada para o período de 20 a 25 de abril de 2004. Os resultados apresentados foram extraídos da quarta grade do modelo RAMS, com resolução de $40 \mathrm{~km}$ x $40 \mathrm{~km}$, centrada nas coordenadas da Usina Termoelétrica Presidente Médici $\left(31.50^{\circ} \mathrm{S}\right.$ e $\left.53.68^{\circ} \mathrm{W}\right)$.

Elevadas taxas de concentração foram simuladas para os três poluentes investigados no dia 21/4/2004. As concentrações máximas de $\mathrm{PM}_{10}, \mathrm{SO}_{2}$ e NOx, foram da ordem de $170 \mu \mathrm{g} \mathrm{m}^{-3}$, ao nível do solo, e distribuídas em regiões muito próximas da fonte emissora. As concentrações elevadas de poluentes junto a fonte podem estar relacionadas com a fraca intensidade dos ventos do quadrante sudoeste, no dia 20/4/2004, o que pode ter dificultado a mistura na camada limite planetária e o arraste dos poluentes a maiores distâncias, caracterizando o comportamento simulado. Entretanto, a incidência de ventos do quadrante sudoeste deslocou a pluma de poluentes para nordeste, ocasionando a dispersão de poluente a longas distâncias, cerca de $20 \mathrm{~km}$ da fonte emissora. Em regiões distantes da fonte emissora foram simulados níveis de concentração entre 40 a $60 \mu \mathrm{g}$ $\mathrm{m}^{-3}$ para $\mathrm{PM}_{10}, \mathrm{SO}_{2}$ e $\mathrm{NO}_{\mathrm{x}}$.

Analisando o efeito da topografia no comportamento da dispersão dos poluentes na região de Candiota, observou-se que os que ventos desorganizados do quadrante sul provocaram o arraste da pluma na encosta da pequena elevação existente a leste da UTPM, o que bloqueou o escoamento do vento, causando deposição do material poluente na altura de $31.50^{\circ} \mathrm{S}$ e $53.62^{\circ} \mathrm{W}$. A recirculação gerada pela presença da topografia forçou a parcela de ar a se diri- 
gir em direção norte e nordeste, onde encontrou uma região de vale, o que possibilitou o transporte de poluentes para outras regiões. A influência topográfica na dispersão de poluentes na região de Candiota é corroborada em Karam et al. ${ }^{11}$ e Alves ${ }^{6}$.

De acordo com a descrição das condições atmosféricas do período estudado, o dia 21/4/2004 antecedeu a entrada de um sistema frontal, verificando-se a intensificação dos ventos do quadrante leste para nordeste no decorrer do período. As concentrações médias para o dia 21/4/2004 indicaram a distribuição de níveis concentrações da ordem de 5 a $10 \mu \mathrm{g} \mathrm{m}^{-3}$ no setor noroeste, para os três poluentes investigados, provavelmente provocadas pela incidência de ventos do quadrante leste durante as primeiras horas do dia. Com a intensificação dos ventos do quadrante nordeste a pluma de poluentes deslocou-se na direção sudoeste, dispersando-os para regiões afastadas da usina. $\mathrm{PM}_{10}$ e $\mathrm{NO}_{\mathrm{x}}$ apresentaram concentrações similares neste dia onde máximos da ordem de $27 \mu \mathrm{g} \mathrm{m}^{-3}$ foram simuladas em pontos da superfície distantes até $7 \mathrm{~km}$ da fonte, devido à acentuada turbulência de origem mecânica. As concentrações de $\mathrm{SO}_{2}$ no dia 21/4/2004 apresentaram um transporte organizado na direção sudoeste atingindo níveis de até $30 \mu \mathrm{g} \mathrm{m}^{-3}$ em áreas próximas à UTPM.

Karam et al. ${ }^{11}$ realizaram estudo da simulação numérica da dispersão de $\mathrm{SO}_{2}$ na região de Candiota aplicando um modelo aleatório de partículas (RDM), que para o dia 11/2/1995 apresentou resultados de concentração média diária simulada para a superfície valores máximos entre 60 e $80 \mu \mathrm{g} \mathrm{m}^{-3}$. Os resultados simulados em anos diferentes mostraram que houve uma redução nos níveis de $\mathrm{SO}_{2}$ para o último ano.

No dia 22/4/2004 concentrações da ordem de $15 \mu \mathrm{g} / \mathrm{m}^{3}$ de $\mathrm{PM}_{10}$ e $\mathrm{NO}_{\mathrm{x}}$ e máximos de $10 \mu \mathrm{g} \mathrm{m}^{-3}$ de $\mathrm{SO}_{2}$ foram verificados a cerca de $6,5 \mathrm{~km}$ de distância da fonte emissora. $\mathrm{O}$ fato dos centros de concentrações mais altas estarem afastadas da fonte emissora é explicado pelo fraco transporte vertical, assim como pelo predomínio de ventos intensos, que arrastam os poluentes em níveis mais elevados da atmosfera, impedindo que estes fossem depositados próximos à fonte de emissão.

No dia 23/4/2004 as concentrações para os três poluentes estudados ficaram em torno de $9 \mu \mathrm{g} \mathrm{m}^{-3} \mathrm{em}$ pontos situados, aproximadamente, $8 \mathrm{~km}$ a sudeste da fonte emissora. Isto pode ser explicado devido à predominância dos ventos do quadrante noroeste, com variação para a direção sudoeste no início da tarde, ocasionaram a dispersão da pluma de poluentes para esta direção.

As concentrações simuladas no dia 24/4/2004 tiveram máximos simulados na ordem de $33 \mu \mathrm{g} \mathrm{m}^{-3}$ para $\mathrm{SO}_{2}$ e $22 \mu \mathrm{g} \mathrm{m} \mathrm{g}^{-3}$ para $\mathrm{PM}_{10}$ e $\mathrm{NO}_{\mathrm{x}}$. Porém, observaram-se ramificações na pluma de poluentes, seguindo justamente a variação no sentido do vento observada ao longo do dia. Os centros de maiores concentrações apresentaram-se na direção nordeste, quando o efeito da dispersão era basicamente controlado pela turbulência de origem mecânica. À medida que o dia avançou, a quantidade de radiação que atingia a superfície mantinha o processo convectivo intenso, observando-se um aumento da atividade turbulenta, porém de origem térmica. Fatores como a energia advectiva pelo processo de aquecimento do ar, ventos moderados de sul, associados ao suprimento adicional de umidade no solo após a precipitação ocorrida em dias anteriores foram responsáveis pelos processos mais intensos de transferência de calor e umidade, possibilitando maior eficiência no transporte vertical dos poluentes na atmosfera. Durante o período diurno, quando atuavam estas condições de turbulência expressiva, os valores não excederam a ordem de $16 \mu \mathrm{g} \mathrm{m}^{-3}$ de concentração para $\mathrm{PM}_{10}$ e $\mathrm{NO}_{\mathrm{x}}$ e de $24 \mu \mathrm{g} \mathrm{m}{ }^{-3}$ para $\mathrm{SO}_{2}$.

Em pontos situados próximos à UTPM as concentrações foram superiores a $60 \mu \mathrm{g} \mathrm{m}^{-3}$ de $\mathrm{SO}_{2}$ e da ordem de $65 \mu \mathrm{g} \mathrm{m}^{-3}$ para $\mathrm{PM}_{10} \mathrm{e}$ $\mathrm{NO}_{x}$ no dia 25/4/2004. Provavelmente o transporte de poluentes foi dificultado pela falta de ventos da componente sul e com baixa intensidade tenham favorecido a entrada de uma massa de ar mais fria e seca, impedindo que a atividade convectiva ganhasse força suficiente para a dispersão local dos poluentes.

De forma geral, a variação das concentrações mostrou valores maiores próximos à fonte emissora e menores mais distantes da fonte. O comportamento da dispersão de poluentes na região de Candiota é confirmado analisando-se outros estudos realizados na região $0^{6,9,11}$, que evidenciaram o acúmulo das concentrações de poluente junto à fonte emissora quando da ocorrência de ventos fracos e da influência das características orográficas como determinantes no escoamento do vento e na dispersão dos poluentes.

\section{Comparação entre dados observados e modelados: $\mathrm{PM}_{10}$ e $\mathrm{SO}_{2}$}

Na estação Três Lagoas situada a sudoeste da UTPM foram obtidas concentrações máximas de $\mathrm{SO}_{2}$ de $18 \mu \mathrm{g} \mathrm{m}^{-3}$, no dia $21 / 4 \mathrm{e}$ de $5,8 \mu \mathrm{g} \mathrm{m}^{-3}$, no dia 22/4/2004 (Figura 5). Para os demais dias as concentrações simuladas com o modelo RAMS ficaram próximas de zero. As concentrações observadas de $\mathrm{SO}_{2}$ para os dias 21 e 22/ $4 / 2004$ foram de 13 e $3 \mu \mathrm{g} \mathrm{m}^{-3}$, respectivamente. Nos demais dias analisados as concentrações medidas e prognosticadas foram similares, ficando próximas de zero.

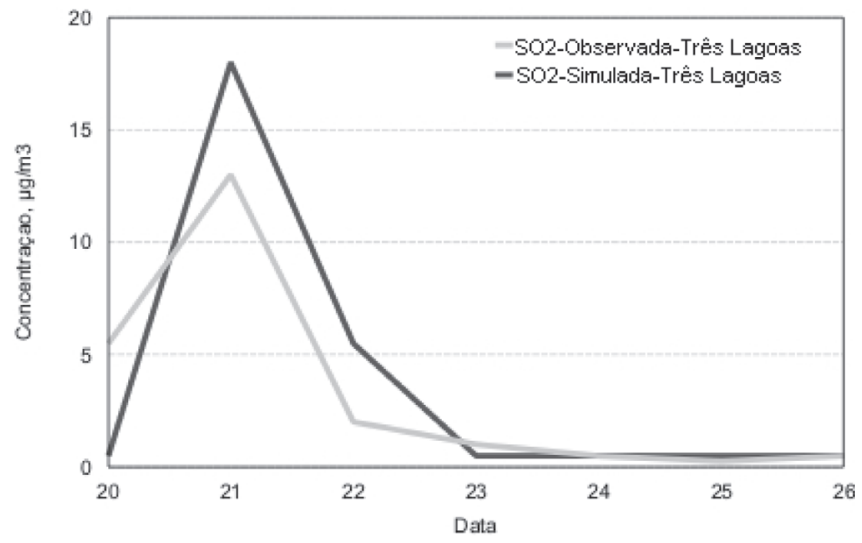

Figura 5. Concentrações observada e simulada de $\mathrm{SO}_{2}$ na estação Três Lagoas

As concentrações simuladas de $\mathrm{PM}_{10}$ para a estação Três Lagoas apresentaram valores de $22,5 \mu \mathrm{g} \mathrm{m}^{-3}(21 / 4 / 2004)$ e de $5 \mu \mathrm{g} \mathrm{m}^{-3}$ (22/4/2004). No decorrer do período as concentrações de $\mathrm{PM}_{10}$ foram prognosticadas como nulas. Os resultados obtidos através das coletas de $\mathrm{PM}_{10}$ realizadas no período estudado apresentam perfil bastante distinto do simulado, apresentando erro normalizado de $89 \%$ comparando-os com os dados de concentração simulados. As concentrações medidas nos dias 21 e 22/4/2004 foram de 13 e 11 $\mu \mathrm{g} \mathrm{m}^{-3}$, respectivamente (Figura 6 ) e foi constatada a elevação das concentrações de $\mathrm{PM}_{10}$ no decorrer do período chegando a $24 \mu \mathrm{g}$ $\mathrm{m}^{-3}$, no dia 26/04/2004.

As concentrações simuladas e observadas de $\mathrm{SO}_{2}$ na estação Aeroporto de Candiota são apresentadas na Figura 7. O $\mathrm{SO}_{2}$ simulado para a estação mostrou valor 2,3 vezes maior que o observado no dia 20/4, atingindo $14 \mu \mathrm{g} \mathrm{m}^{-3}$. Nos demais dias as concentrações foram baixas, em torno de $3 \mu \mathrm{g} \mathrm{m}^{-3}$, menores que as concentrações medidas na estação. Tendo em vista as condições atmosféricas apresentadas no item acima, os ventos predominantes durante o período simulado de sul-sudoeste, provocaram a dispersão dos poluentes simulados na direção oposta da localização da estação de monitoramento. Com isso, os resultados comparados apresentam tais disparidades, principalmente nos dias em que as direções do vento 


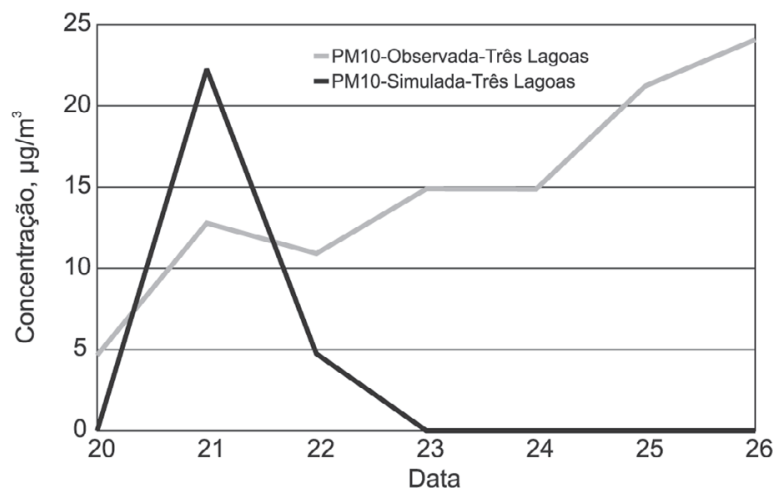

Figura 6. Concentrações observada e simulada de $P M_{10}$, na estação Três Lagoas

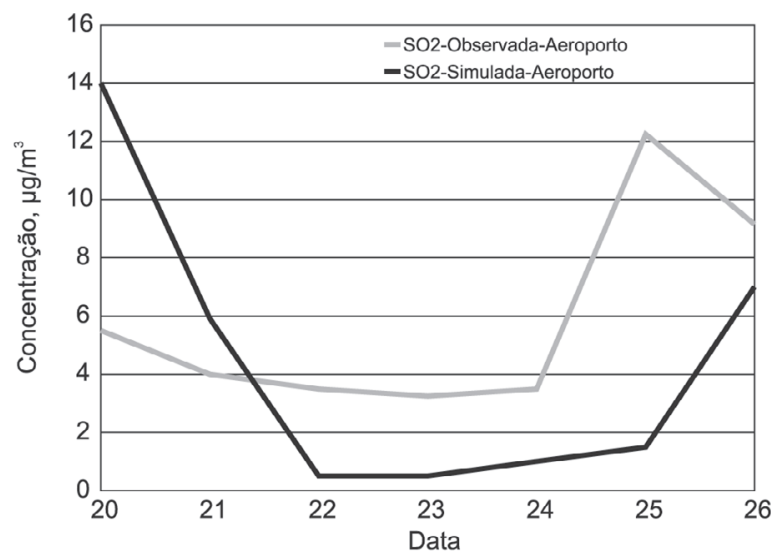

Figura 7. Concentrações observada e simulada de $\mathrm{SO}_{2}$ na estação Aeroporto.

favoreceram a dispersão do $\mathrm{SO}_{2}$ para regiões afastadas da estação.

As Figuras 8 e 9 apresentam as concentrações simuladas e medidas de $\mathrm{PM}_{10}$ para as estações 8 de Agosto e Aceguá, respectivamente. Localizadas a sudoeste da UTPM, as estações de monitoramento estão na direção contrária à da pluma de dispersão dos poluentes simulados para o período analisado, de acordo com as condições atmosféricas citadas no item acima. Diante disso, apenas no dia 21/4 as concentrações prognosticadas foram de 13 $\mu \mathrm{g} / \mathrm{m}^{3}$ ( 8 de Agosto) e de $4 \mu \mathrm{g} \mathrm{m}^{-3}$ (Aceguá), sendo que nos demais dias simulados não foram obtidos valores de concentrações de $\mathrm{PM}_{10}$. Os dados medidos na estação apresentaram concentrações que variaram de 1 a $21 \mu \mathrm{g} \mathrm{m}^{-3}$, na estação 8 de Agosto e de 3 a 20,5 $\mu \mathrm{g} \mathrm{m}^{-3}$, em Aceguá, verificando-se picos de concentração no dia 21/4 devido às condições de instabilidade atmosférica que promoveram o acúmulo das concentrações de material particulado.

De acordo com as comparações entre as concentrações medidas e simuladas de $\mathrm{SO}_{2}$ e $\mathrm{PM}_{10}$ verificou-se, de modo geral, que as concentrações prognosticadas estão diretamente relacionadas com a sensibilidade do modelo às condições atmosféricas simuladas como o campo de vento. Foi verificada a subestimação das concentrações modeladas em relação aos dados observados nos dias em que os ventos modelados foram do quadrante sul-sudoeste e oeste-noroeste, pois estes provocaram a dispersão dos poluentes em direções opostas àquelas das estações de monitoramento analisadas neste estudo. Segundo Alves ${ }^{9}$, de modo geral, os modelos de dispersão subestimam os valores de concentração quando comparados aos valores medidos, por utilizarem dados empíricos de estabilidade atmosférica.

Com relação às concentrações de $\mathrm{SO}_{2}$ e $\mathrm{PM}_{10}$ superestimadas no dia 21/4, na estação Três Lagoas estão relacionadas com a inci-

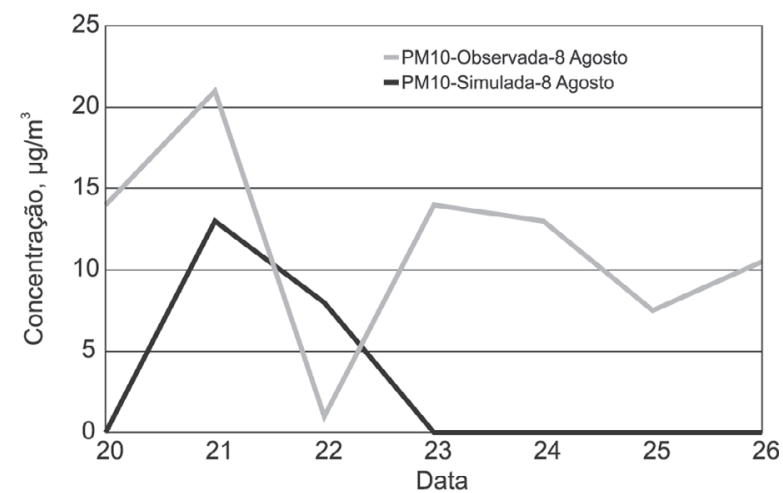

Figura 8. Concentrações observada e simulada de $P M_{10}$, na estação de 8 de Agosto

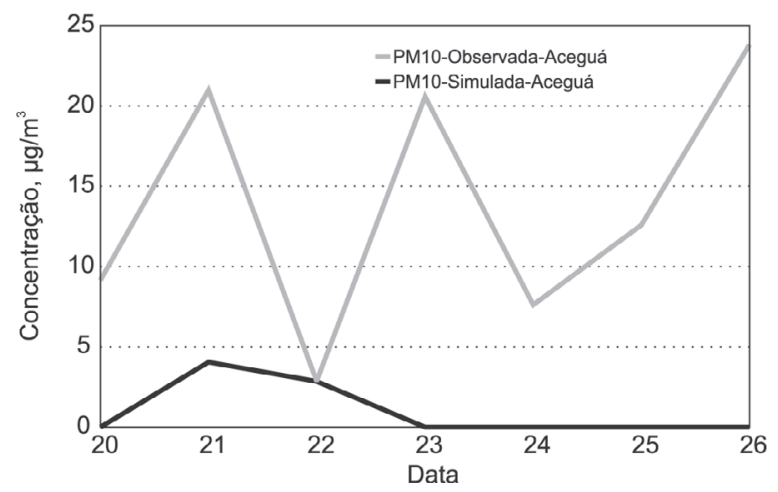

Figura 9. Concentrações observada e simulada de $P M_{10}$ na estação Aceguá

dência de ventos do quadrante leste-nordeste. De acordo com as características orográficas da região estudada o escoamento do vento, quando este é do quadrante leste-nordeste, ocasiona o acúmulo de poluentes junto à usina. Estas observações são corroboradas por Alves ${ }^{6}$, que utilizando o modelo RAMS para a predição das concentrações de $\mathrm{SO}_{2}$ na região de Candiota obteve valores de $20 \mu \mathrm{g} \mathrm{m}^{-3}$, para os dias 23 e 24/8/1999 e de $15 \mu \mathrm{g} \mathrm{m}^{-3}$ no dia 25/ 8/1999, na estação Três Lagoas. Na estação Candiotão, localizada a $6 \mathrm{~km}$ oeste da fonte, as médias diárias de concentrações, para o mesmo período simulado, foram de $10 \mu \mathrm{g} \mathrm{m}^{-3}$ para o dia 23/8/1999 e nulas nos outros dois dias, devido à incidência de ventos de lestenordeste e da elevação topográfica do terreno.

\section{CONCLUSÕES}

A aplicação de modelagem numérica permitiu o estudo da dispersão do material poluente emitido pela Usina Termoelétrica Presidente Médici, em Candiota - RS.

Os resultados revelam contribuição marcante em relação ao efeito da topografia na região. A pequena elevação da topografia existente provoca um desvio na parcela de ar ao encontrar o desnível topográfico em direção ao vale existente na região da UTPM.

No presente estudo, dentre os dias analisados, o setor noroeste apresentou uma tendência positiva para o transporte de poluentes, justamente pela contribuição associada à orografia local. A topografia presente provoca a canalização em baixos níveis no transporte de poluentes que, ao serem arrastados em direção nordeste, são forçados a entrar no pequeno vale, possibilitando o transporte de poluentes para outras regiões, principalmente as localizadas a sudoeste da usina.

De forma geral, as concentrações simuladas e medidas de $\mathrm{PM}_{10}$ e $\mathrm{SO}_{2}$ apresentaram valores diferentes, devido à subestimação dos 
dados simulados pelo modelo RAMS. Uma das explicações é que as condições meteorológicas simuladas podem não ter sido representativas das condições reais.

\section{MATERIAL SUPLEMENTAR}

As Figuras $1 \mathrm{~S}$ a $6 \mathrm{~S}$, relativas à análise da circulação atmosférica, e as figuras $7 \mathrm{~S}$ a $12 \mathrm{~S}$, relativas à análise das concentrações de $\mathrm{PM}_{10}, \mathrm{SO}_{2}$ e $\mathrm{NO}_{\mathrm{x}}$, encontram-se disponíveis gratuitamente em http:/ /quimicanova.sbq.org.br, na forma de arquivo PDF.

\section{AGRADECIMENTOS}

Ao CNPq pelo suporte financeiro. À CGTEE pelo apoio técnico.

\section{REFERÊNCIAS}

1. Teixeira, E. C.; Pires, M. J. R.; Cadernos de planejamento e gestão ambiental, 4, FINEP/PADCT/CIAMB?FAPERGS/FEPAM: Porto Alegre, 2004.
2. Stull, R. B.; An Introduction to Boundary Layer Meteorology, Kluwer Academic Publishers, Boston: 1988.

3. Nicholls, M. E.; Pielke, R. A.; Eastman, J. L.; Finley, C. A.; Lyons, W. A.; Tremback, C. J.; Walko, R. L.; Cotton, W. R. Em Wind Climate in Cities; Cermak, J. E. ed.; 1995, p. 703-732.

4. Pielke, R. A.; Cotton, W. R.; Walko, L. R.; Tremback, C. J.; Lyons, W. A.; Grasso, L. D.; Nicholls, M. E.; Moran, M. D.; Wesley, D. A.; Lee, T. J.; Copeland, J. H.; Meteorol. Atmos. Phys. 1992, 49, 69.

5. Freitas, E. D.; Tese de Doutorado, Universidade de São Paulo, Brasil, 2003.

6. Alves, R. C. M.; Tese de Doutorado, Universidade de São Paulo, Brasil, 2000.

7. Cotton, W. R.; Pielke, R. A.; Walko, R. L.; Liston, G. E.; Tremback, C. J.; Jiang, H.; McAnelly, R. L.; Harrington, J. Y.; Nicholls, M. E.; Carrio, G. G.; McFadden, J. P.; Meteorol. Atmos. Phys. 2003, 82, 5.

8. Freitas, S. R.: Tese de Doutorado, Universidade de São Paulo, 1999.

9. Alves, R. C. M.; Dissertação de Mestrado, Universidade de São Paulo, Brasil, 1996

11. Karam, H. A.; Oliveira, A. P.; Soares, J.; Carvalho, J. C.; Moraes, O. L. L.; Degrazia, G. A.; Bornstein, N. R. D. Em Air Pollution and Acid Rain: The Candiota Program; Moraes, O. L. L.; Oliveira, A.P.; Caetano Neto, E.S.; Degrazia, G.A., eds.; FAPESP: Bauru, 1996, p. 86.

10. Lasry, F.; Coll, I.; Buisson, E.; Atmos. Res. 2005, 74, 194. 
UTILIZAÇÃO DE MODELAGEM NUMÉRICA PARA O ESTUDO DA DISPERSÃO DE POLUENTES EMITIDOS PELA USINA TERMOELÉTRICA PRESIDENTE MÉDICI

Sheila Radann Paz e Rita Cássia Marques Alves

Centro Estadual de Pesquisas em Sensoriamento Remoto e Meteorologia, Universidade Federal do Rio Grande do Sul, CP 15044, 91501-970 Porto Alegre - RS, Brasil

Elba Calesso Teixeira* e Juliana Braga Dallarosa

Fundação Estadual de Proteção Ambiental Henrique Luís Roessler/RS, Rua Carlos Chagas, 55, 90030-020 Porto Alegre RS, Brasil

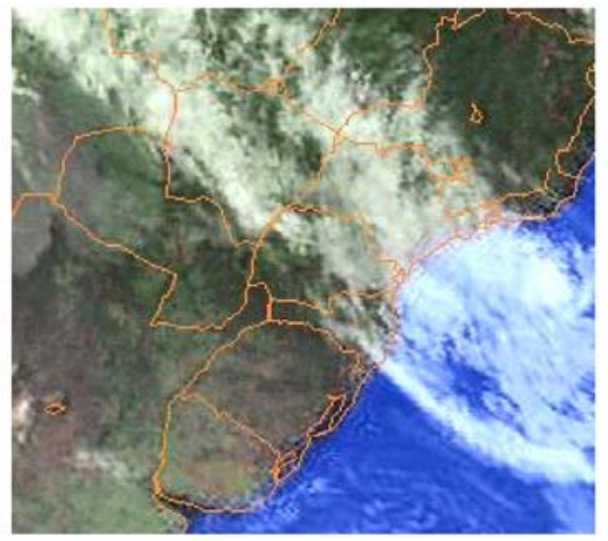

(a) 20/04/2004 02:45 UTC

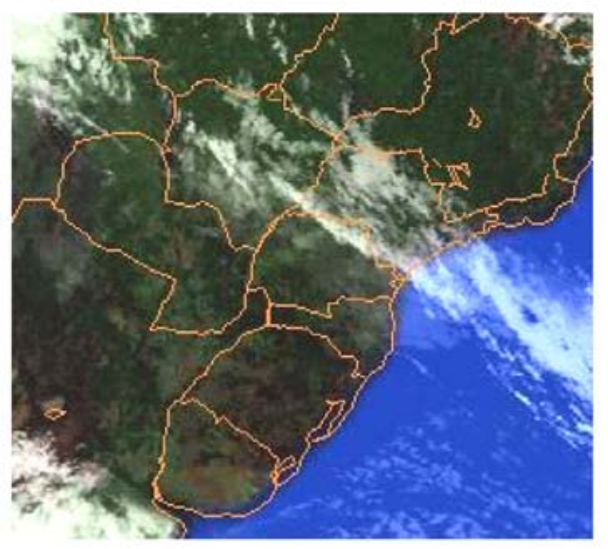

(c) 20/04/2004 14:45 UTC

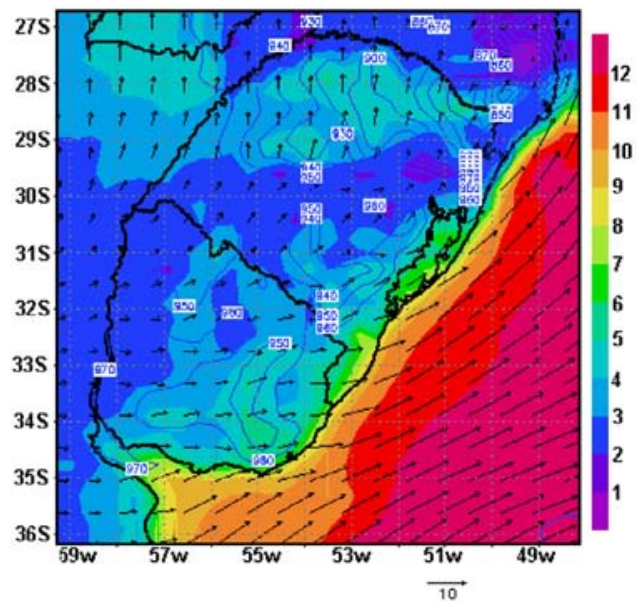

(b) 20/04/2004 03:00 UTC

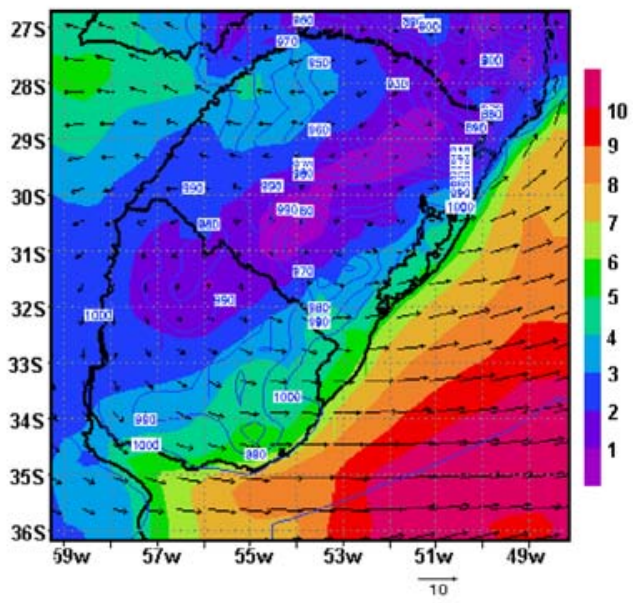

(d) 20/04/2004 15:00 UTC

Figura 1S. Imagem do satélite GOES-12 (coluna da esquerda) e evolução do campo do vento ( $m \mathrm{~s}^{-1}$ ) e pressão atmosférica em hPa (coluna da direita) em nível de 13,4 m acima da superfície. Em (a) 02:45, em (b) 03:00, em (c) 14:45, em (d) 15:00 UTC do dia 20/4/2004. As barras em cores indicam a magnitude do vento 


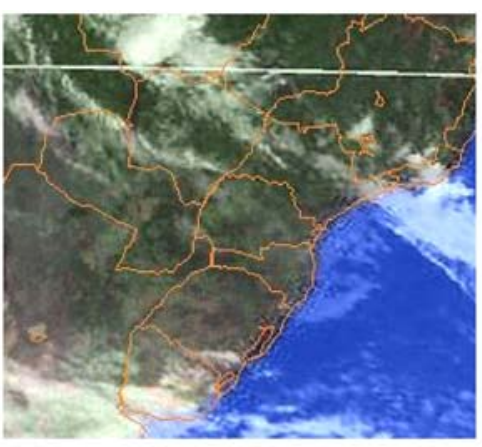

(a) $21 / 04 / 200402: 45$ UTC

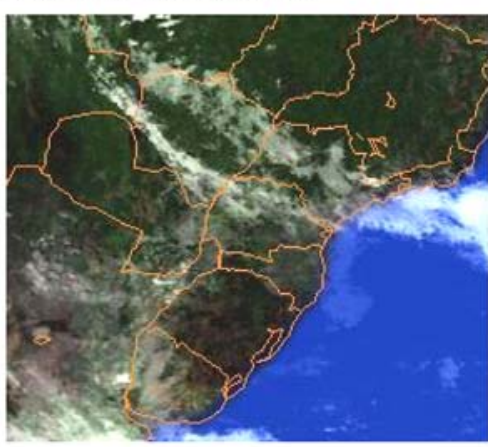

(c) $21 / 04 / 200414: 45$ UTC

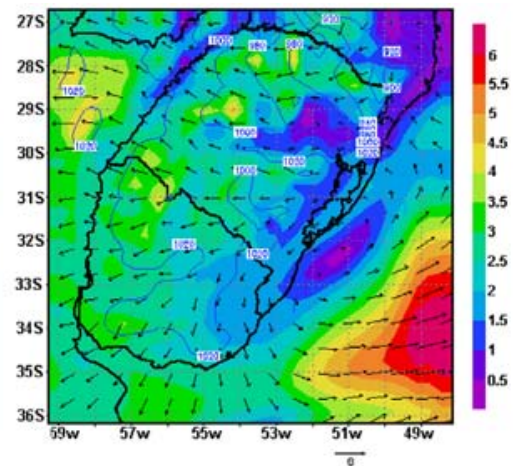

(b) $21 / 04 / 2004$ 03:00 UTC

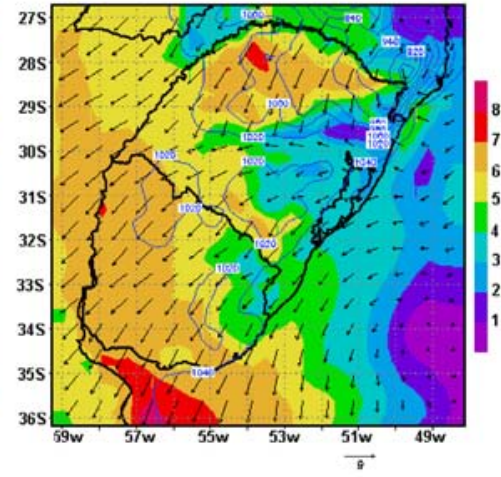

(d) $21 / 04 / 2004$ 15:00 UTC

Figura 2S. Imagem do satélite GOES-12 (coluna da esquerda) e evolução do campo do vento ( $m \mathrm{~s}^{-1}$ ) e pressão atmosférica em hPa (coluna da direita) nível de 13,4 m acima da superfície. Em (a) 02:45, em (b) 03:00, em (c) 14:45, em (d) 15:00 UTC do dia 21/4/2004. As barras em cores indicam a magnitude do vento

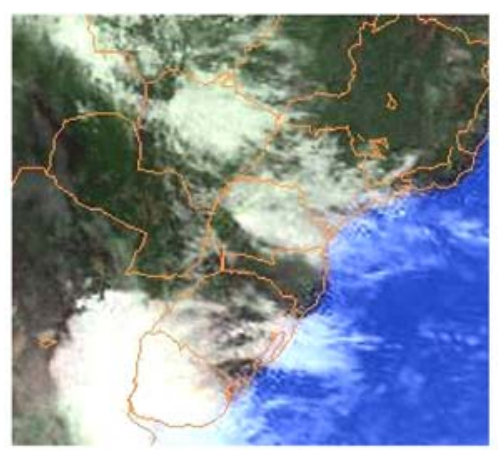

(a) 22/04/2004 02:45 UTC

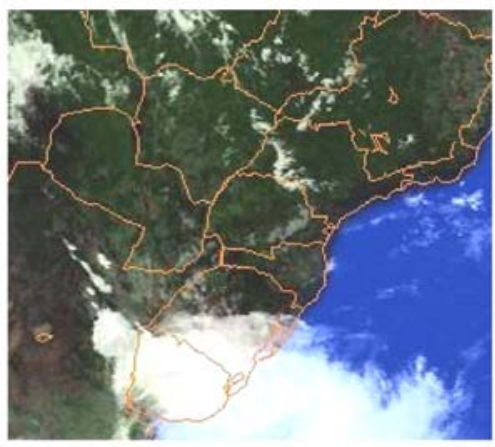

(c) $22 / 04 / 200414: 45$ UTC

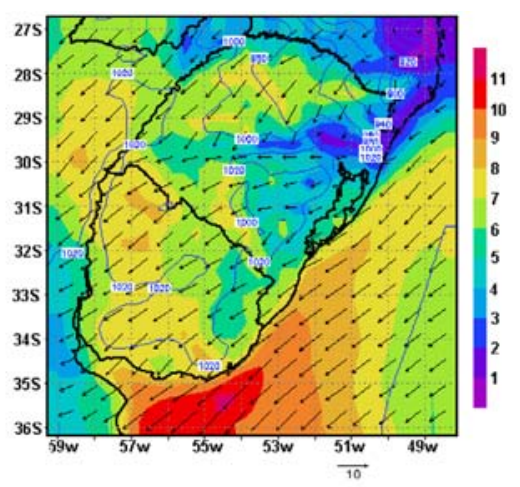

(b) 22/04/2004 03:00 UTC

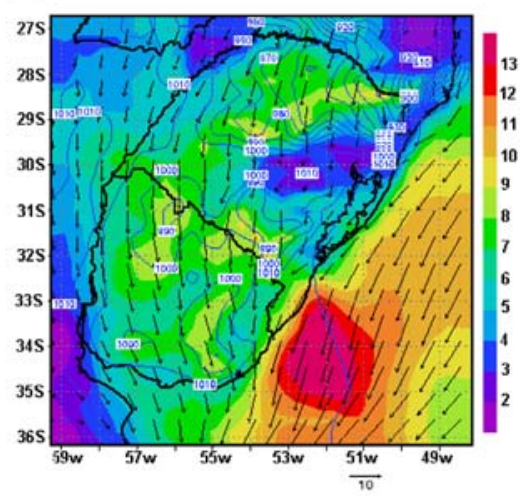

(d) $22 / 04 / 200415: 00$ UTC

Figura 3S. Imagem do satélite GOES-12 (coluna da esquerda) e evolução do campo do vento ( $\mathrm{m} \mathrm{s} \mathrm{s}^{-1}$ ) e pressão atmosférica em mb (coluna da direita) em nível de 13,4 m acima da superfície. Em (a) 02:45, em (b) 03:00, em (c) 14:45, em (d) 15:00 UTC do dia 22/4/2004. As barras em cores indicam a magnitude do vento 


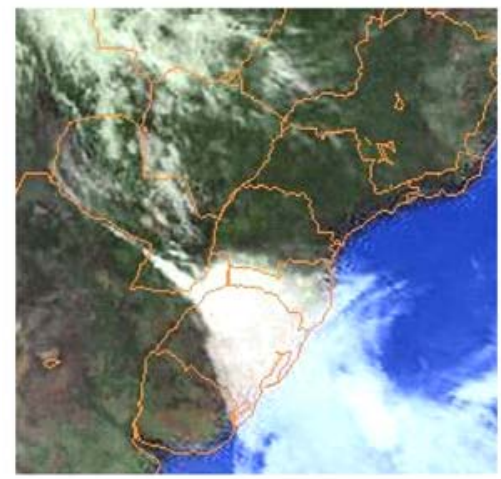

(a) $23 / 04 / 2004$ 02:45 UTC

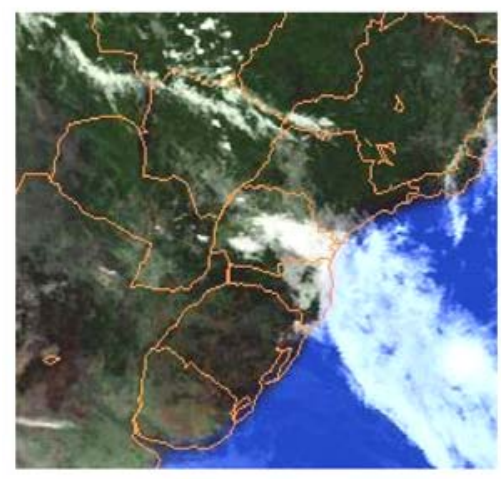

(c) $23 / 04 / 200414: 45$ UTC

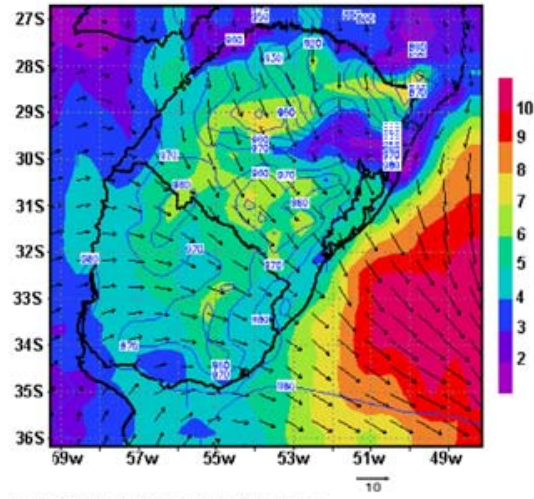

(b) $23 / 04 / 2004$ 03:00 UTC

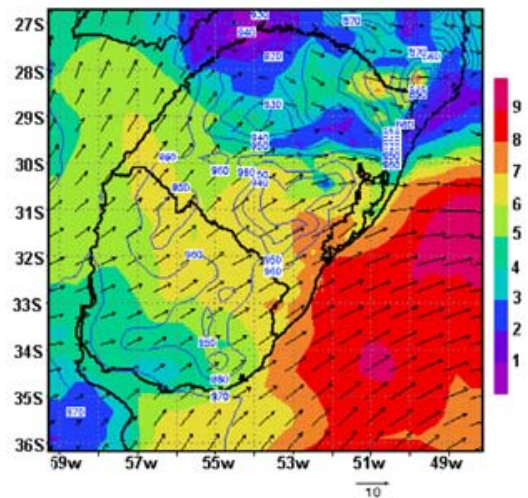

(d) $23 / 04 / 2004$ 15:00 UTC

Figura 4S. Imagem do satélite GOES-12 (coluna da esquerda) e evolução do campo do vento ( $\mathrm{m} \mathrm{s} \mathrm{s}^{-1}$ ) e pressão atmosférica em mb (coluna da direita) em nível de 13,4 m acima da superfície. Em (a) 02:45, em (b) 03:00, em (c) 14:45, em (d) 15:00 UTC do dia 23/4/2004. As barras em cores indicam a magnitude do vento

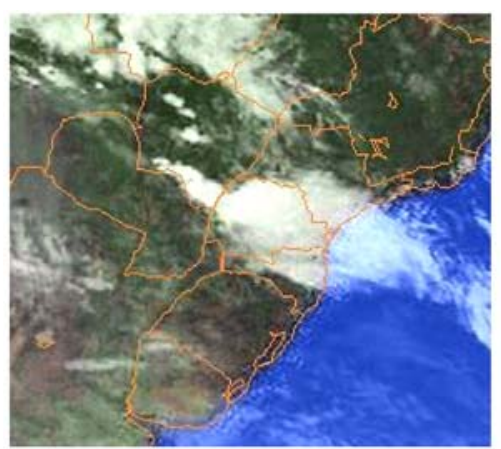

(a) $24 / 04 / 200402: 45$ UTC

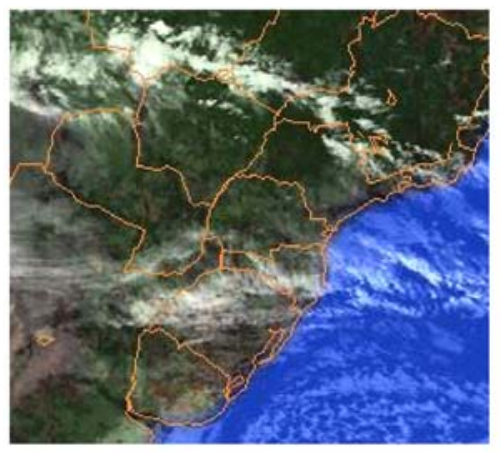

(c) $24 / 04 / 2004$ 14:45 UTC

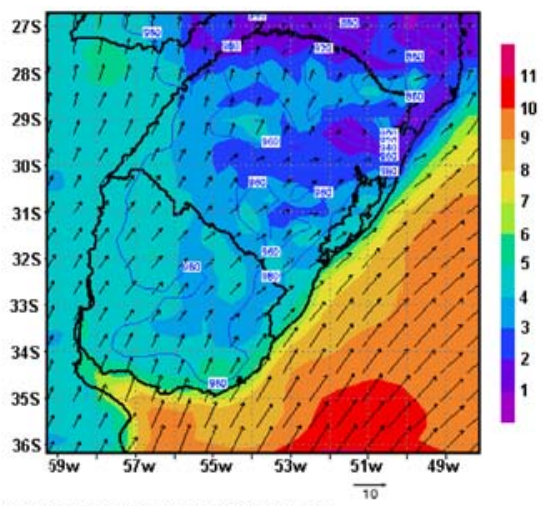

(b) $24 / 04 / 2004$ 03:00 UTC

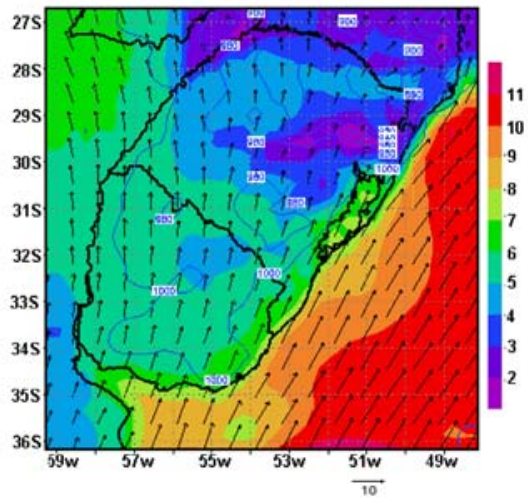

(d) $24 / 04 / 2004$ 15:00 UTC

Figura 5S. Imagem do satélite GOES-12 (coluna da esquerda) e evolução do campo do vento ( $\mathrm{m} \mathrm{s}^{-1}$ ) e pressão atmosférica em mb (coluna da direita) em nível de 13,4 m acima da superfície. Em (a) 02:45, em (b) 03:00, em (c) 14:45, em (d) 15:00 UTC do dia 24/4/2004. As barras em cores indicam a magnitude do vento 


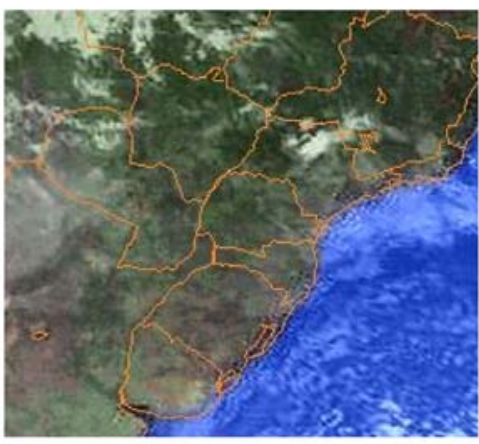

(a) 25/04/2004 02:45 UTC

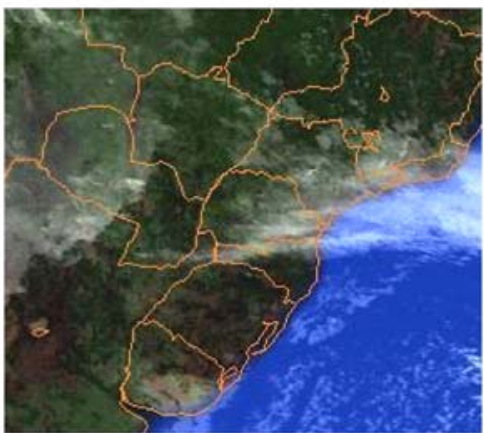

(c) $25 / 04 / 2004$ 14:45 UTC

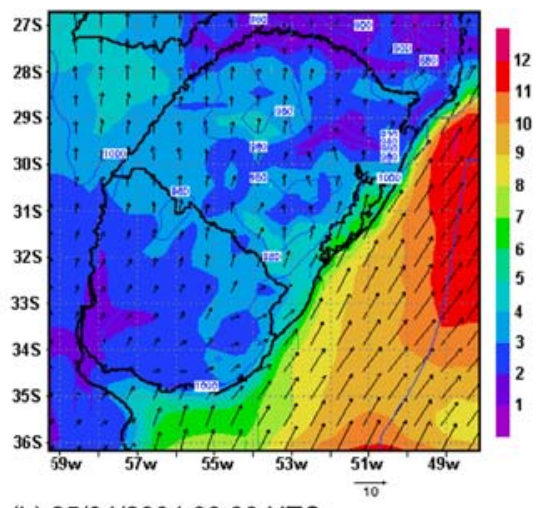

(b) 25/04/2004 03:00 UTC

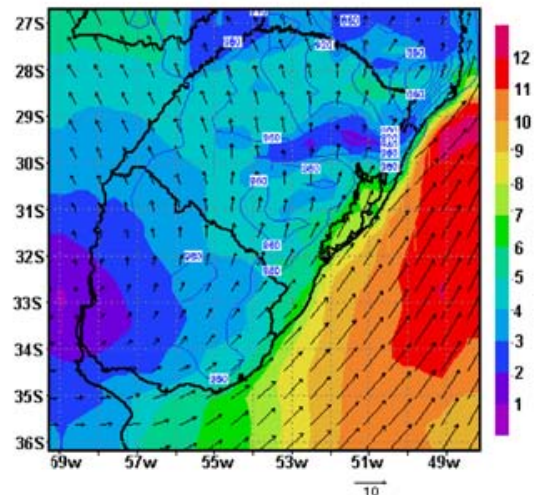

(d) 25/04/2004 15:00 UTC

Figura 6S. Imagem do satélite GOES-12 (coluna da esquerda) e evolução do campo do vento ( $\mathrm{m} \mathrm{s}^{-1}$ ) e pressão atmosférica em mb (coluna da direita) em nível de 13,4 m acima da superfície. Em (a) 02:45, em (b) 03:00, em (c) 14:45, em (d) 15:00 UTC do dia 25/4/2004. As barras em cores indicam a magnitude do vento

As Figuras $7 \mathrm{~S}$ a $12 \mathrm{~S}$ mostram resultados simulados das concentrações médias diárias de $\mathrm{PM}_{10}, \mathrm{SO}_{2}$ e $\mathrm{NO}_{\mathrm{x}}$ expressos em mg m $\mathrm{m}^{-3}$, para o período estudado.

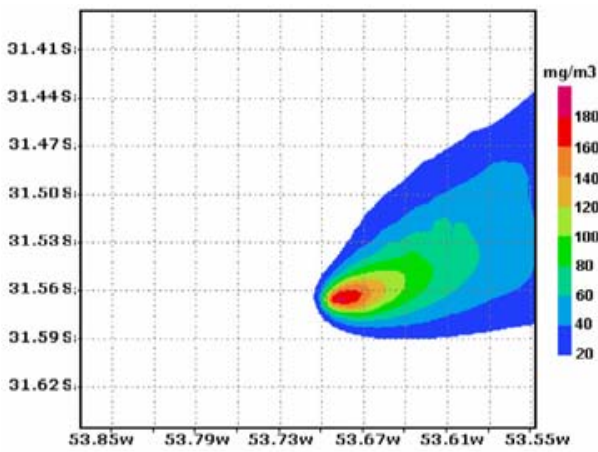

(a) $\mathrm{PM}_{10}$

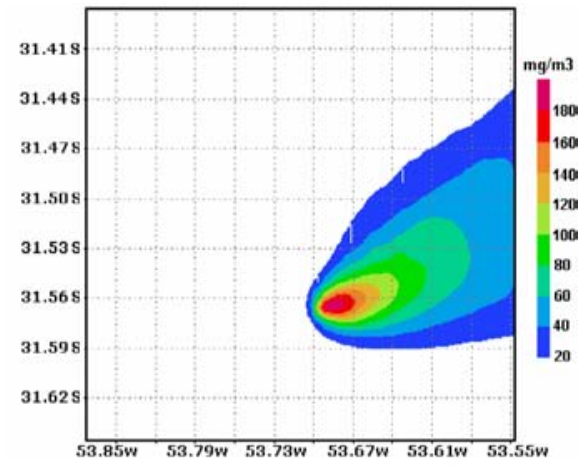

(b) $\mathrm{SO}_{2}$

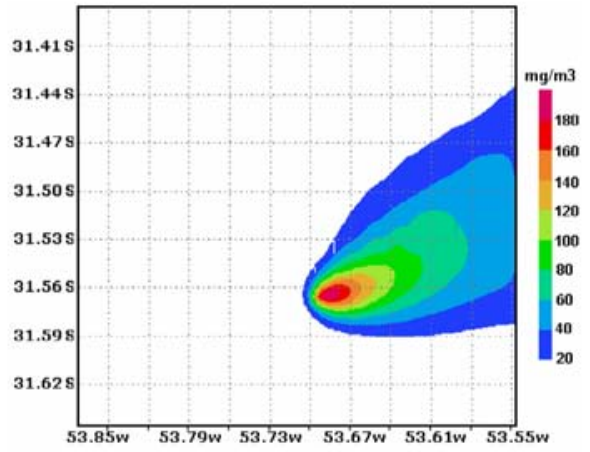

(c) $\mathrm{NO}_{x}$

Figura 7S. Concentração média de $\mathrm{PM}_{10}\left(\right.$ a), $\mathrm{SO}_{2}($ b) e NOx (c) para o dia 20/4/2004 


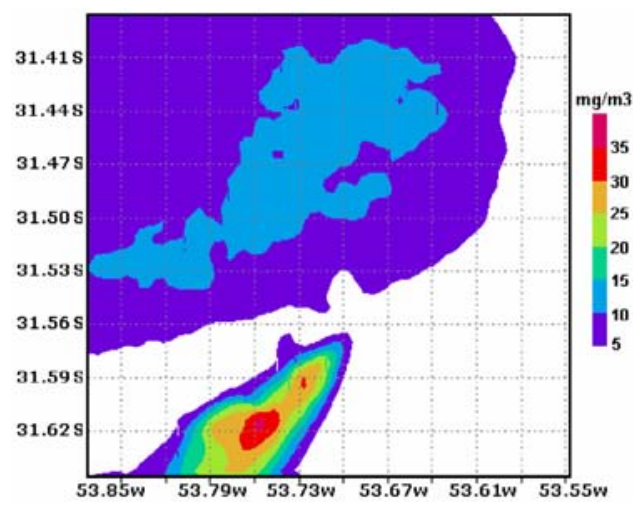

(a) $-\mathrm{PM}_{10}$

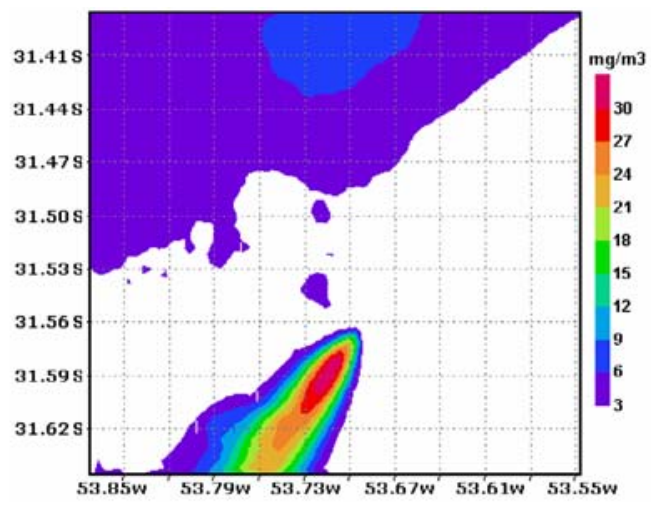

(b) $\mathrm{SO}_{2}$

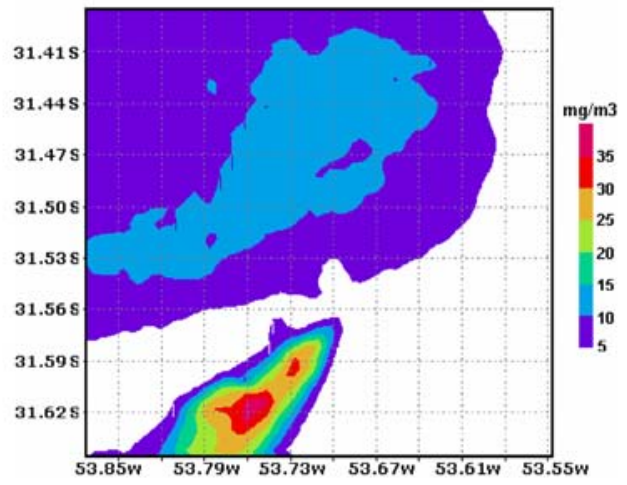

(c) $\mathrm{NO}_{x}$

Figura 8S. Concentração média de $\mathrm{PM}_{10}\left(\right.$ a), $\mathrm{SO}_{2}($ b) e NOx (c) para o dia 21/4/2004

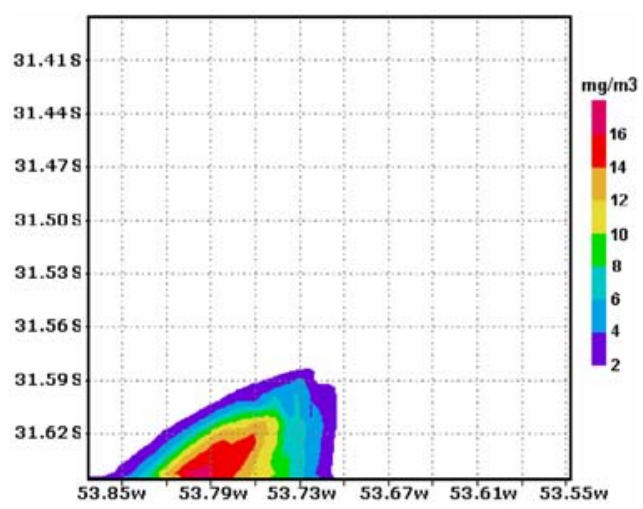

(a) $\mathrm{PM}_{10}$

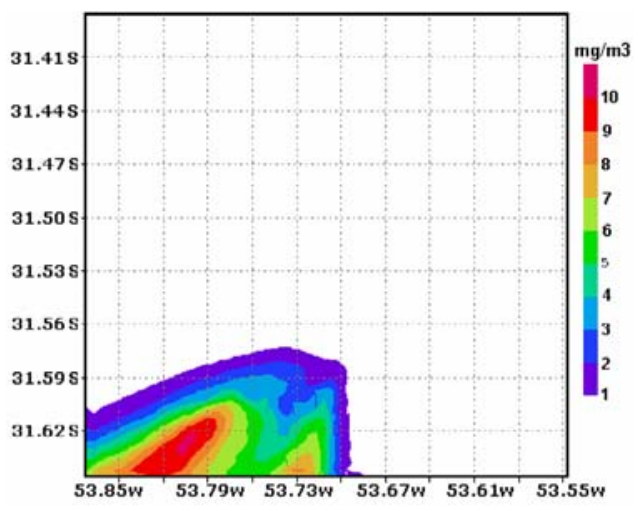

(b) $\mathrm{SO}_{2}$

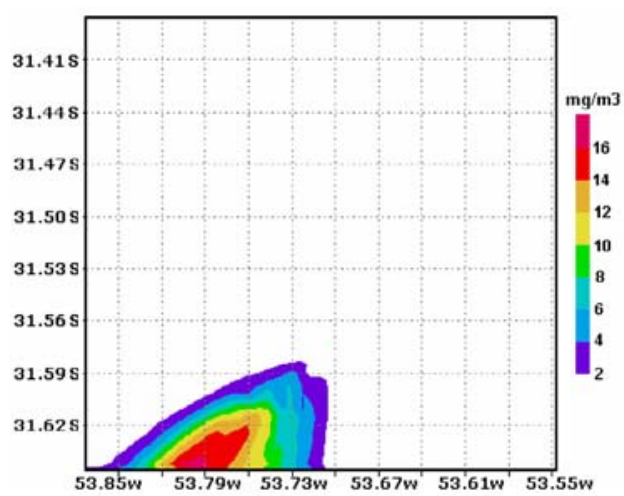

(c) $\mathrm{NO}_{x}$

Figura 9S. Concentração média de $\mathrm{PM}_{10}\left(\right.$ a), $\mathrm{SO}_{2}($ b) e NOx (c) para o dia 22/4/2004 


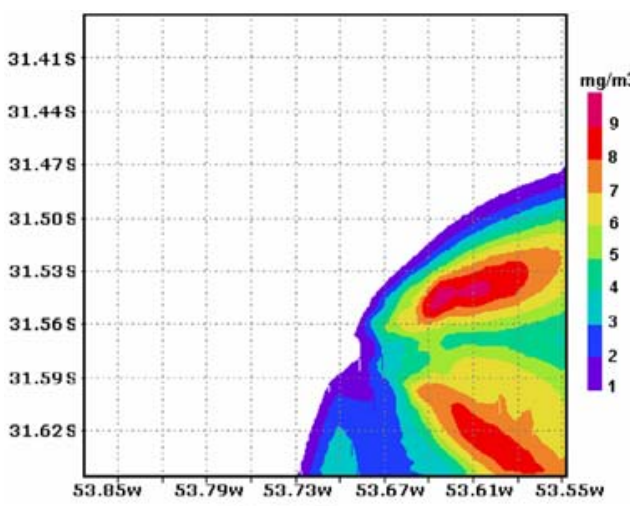

(a) $\mathrm{PM}_{10}$

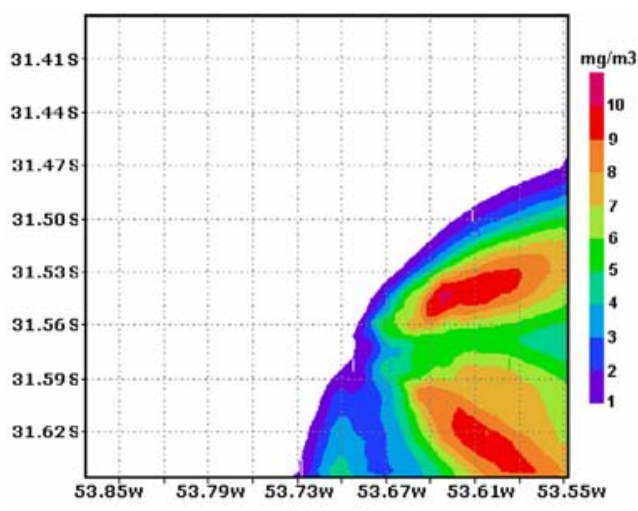

(b) $\mathrm{SO}_{2}$

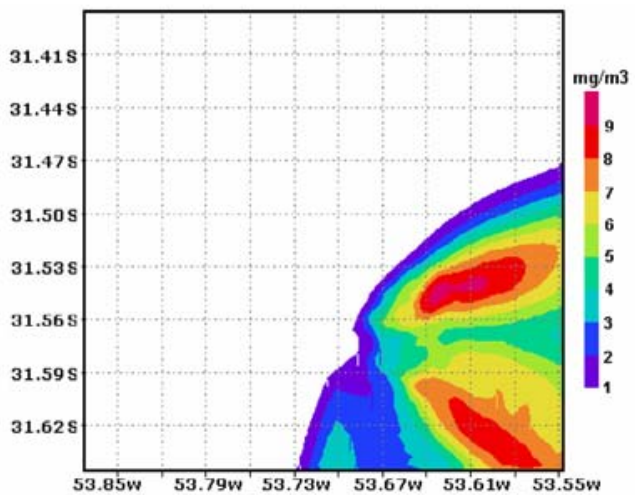

(c) $\mathrm{NO}_{x}$

Figura 10S. Concentração média de $\mathrm{PM}_{10}\left(\right.$ a), $\mathrm{SO}_{2}($ b) e NOx (c) para o dia 23/4/2004

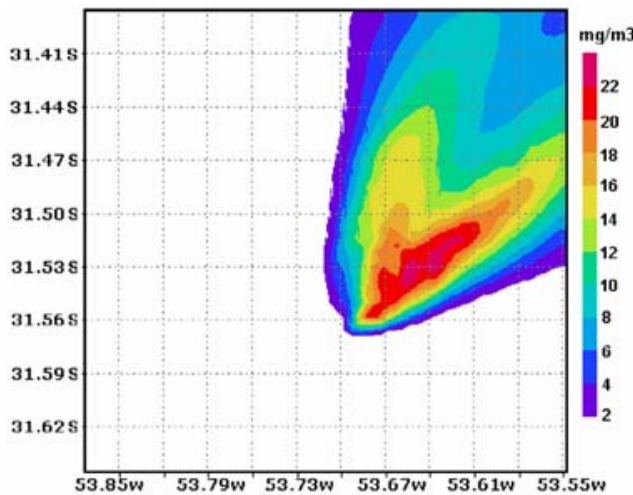

(a) $\mathrm{PM}_{10}$

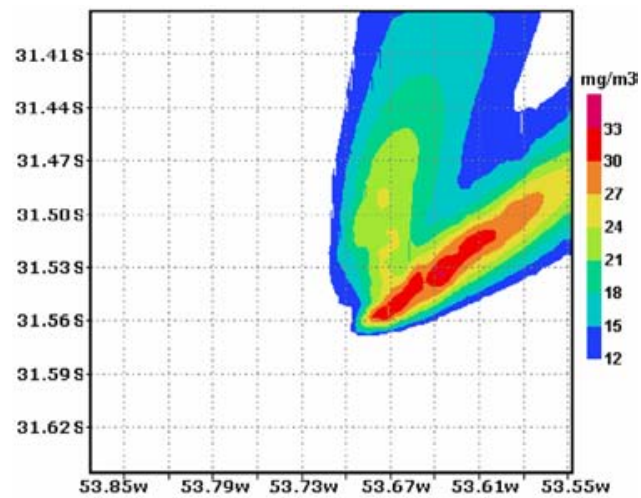

(b) $\mathrm{SO}_{2}$

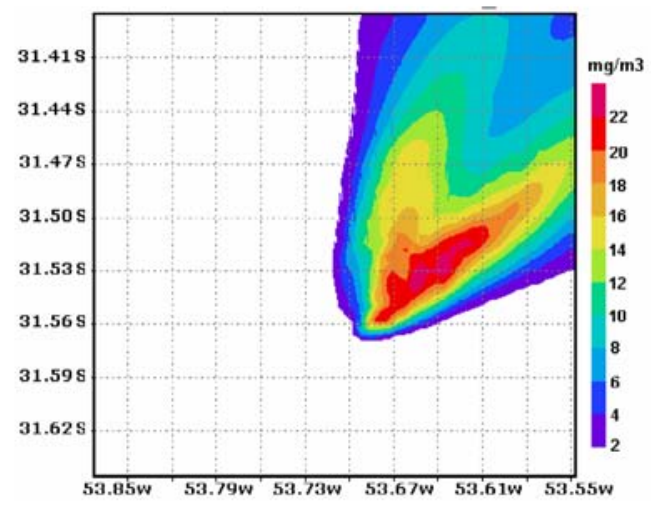

(c) $\mathrm{NO}_{\mathrm{x}}$

Figura 11S. Concentração média de $\mathrm{PM}_{10}\left(\right.$ a), $\mathrm{SO}_{2}($ b) e NOx (c) para o dia 24/4/2004 


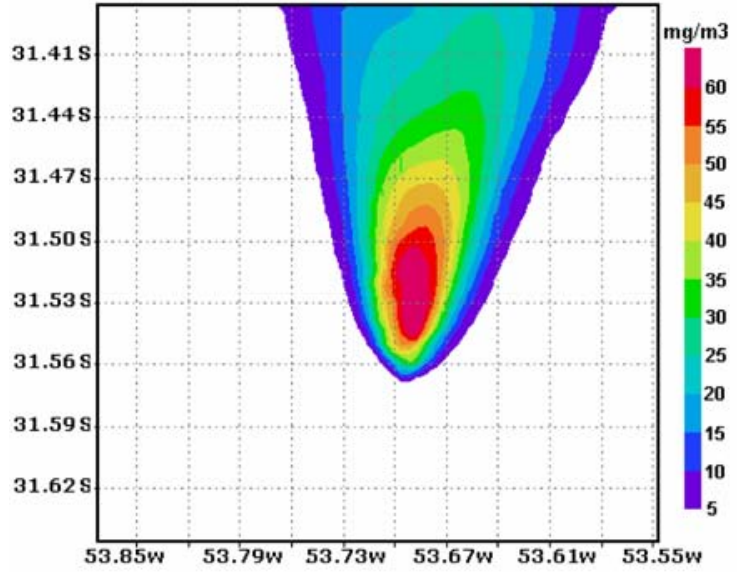

(a) Média do dia 25/04 - $\mathrm{PM}_{10}$

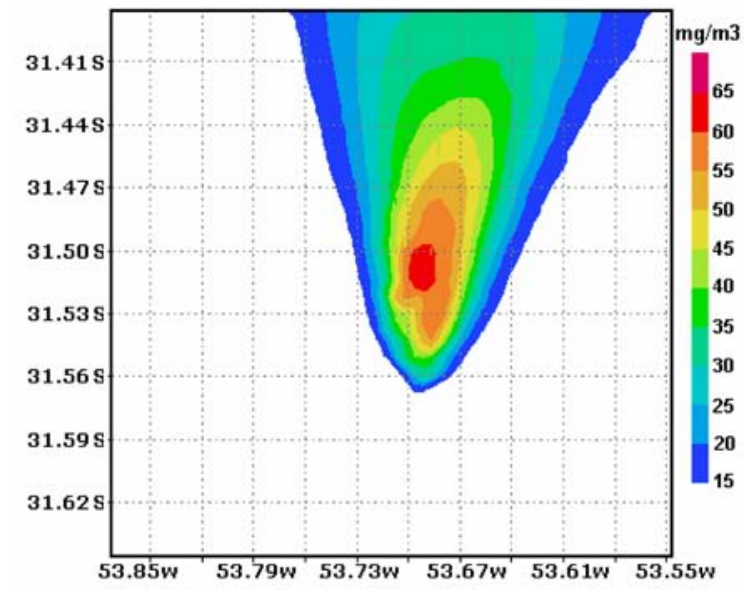

(a) Média do dia 25/04 - $\mathrm{SO}_{2}$

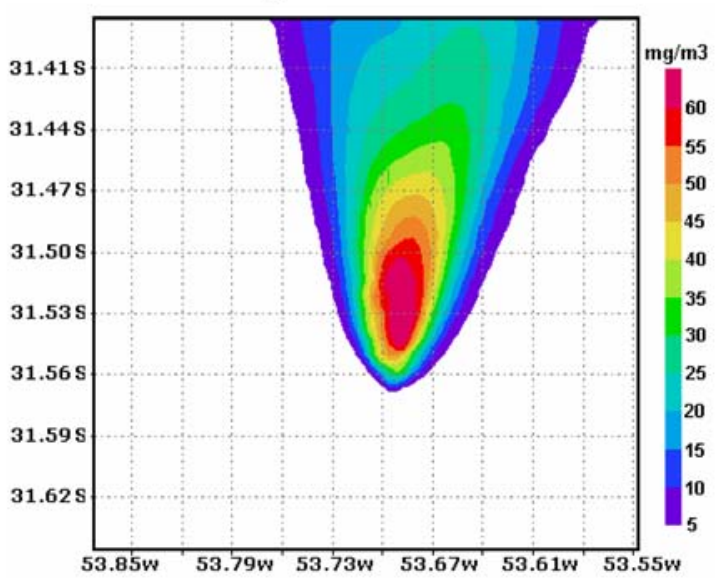

(a) Média do dia 25/04 - $\mathrm{NO}_{\mathrm{x}}$

Figura 12S. Concentração média em $\mu m$ de $\mathrm{PM}_{10}\left(\right.$ a), $\mathrm{SO}_{2}($ b) e NOx (c) para o dia 25/4/2004 